\title{
Practical Study of Water Electrolysis for Solar Powered Hydrogen Production Using Stainless Steel Electrode and Sodium Hydroxide Solution
}

\author{
Gour Chand Mazumder, S M Nasif Shams, Abu Shahadat Md. Ibrahim, Md. Habibur Rahman
}

\begin{abstract}
Water electrolysis is a very well-known and popular method for hydrogen production. The process is simple but there are various aspects to be considered for developing efficient system for water electrolysis. This paper presents a practical study on different electrolysis conditions determining conclusion regarding contributing parameters. Stainless steel plates as electrode and sodium hydroxide solutions are used for data collection. Applying different conditions and physical arrangements the process behavior is observed and recorded for analysis. Theoretical aspects are compared with the observed characteristics of the process. Key aspects of parameters are determined by organized data and analysis. It has been found that the higher molarity of solution increases the current density and gas production rate for same size and same gap of electrode. The scenario is same for the increment of electrode size where gap and molarity is fixed. Gas production is directly proportional to molarity and electrode size. With the reduction of gap between electrodes results increment of current density and gas production at same size of electrode and same molarity of solution. Gas production is inversely proportional to the gap between electrodes. Increment of voltage boosts the gas yields however temperature increases after a certain limit of applied voltage. At that point energy gets wasted through heat and not user for water splitting. Solar photovoltaic panels can easily be used for water electrolysis. Though the radiation gets changed over time the gas production would be according to the voltage and current output.

Index Terms - Electrolysis, Sodium Hydroxide, Gibbs free energy, Nernst equation.
\end{abstract}

\section{INTRODUCTION}

In search of clean fuel technology researchers are working on number of materials. For the clean environment aspect hydrogen comes first as a potential choice. This is because hydrogen can be produced very easily from water through electrolysis. Hydrogen is a renewable element [1]. Burning hydrogen only emits water. So it is considered safe for environment. Usage of hydrogen requires safety concerns as this gas is highly explosive in a particular range of mixture with oxygen [2]. Water electrolysis is very established method for hydrogen production. Industries are using this method for many years. Advanced technologies have already been emerged for efficient results.

The context of countries like Bangladesh is a point of

Gour Chand Mazumder, Institute of Energy, University of Dhaka, Dhaka, Bangladesh

S M Nasif Shams, Institute of Energy, University of Dhaka, Dhaka, Bangladesh

Abu Sahadat Md. Ibrahim, Institute of Energy, University of Dhaka, Dhaka, Bangladesh

Md. Habibur Rahman, Department of EEE, University of Dhaka, Dhaka, Bangladesh interest of this research work. Unhealthy cooking method of rural people is costing lives [3]. According to world health organization indoor air pollution causes million's death. Women and children are directly affected [4]. Small scale solar powered hydrogen generation systems and cooking method using hydrogen gas could become a lifesaving practice [5]. Using Solar photovoltaic panels to electrify the working system would add advantages for the off grid people. Advanced electrolyzers could be replaced by locally developed electrolyzers and short term storage systems using local technologies and materials. In the quest of the appropriate approach to cascade easily found materials, this research is conducted as a background work for a $\mathrm{PhD}$ research project.

Thermal efficiency is an important concern for water electrolysis [6]. Titanium based electrodes are used in most advanced electrolyzers. Along with titanium electrode polymer electrolytic membranes are used for high pressure [7]. These are very costly and not easily found in under developed countries. So it is necessary to find for alternative technology in a practical scale.

\section{IDEAL CHARACTERISTICS OF ELECTROLYSIS}

Water electrolysis is a simple electrochemical process. The characteristics of Water electrolysis are dependent on various parameters. These are so critical that alteration of any will result the varied performance of the whole system. We selected to observe some of the conditions and parameters. The molarity of the electrolytic solution, power source, distance between the electrodes and the size of the electrodes are selected as physical parameters [8]. Whereas imposed voltage, current density, resistivity and temperature are observed as indicating parameters. We varied the physical parameters to collect the data on indicating parameters. Water electrolysis is an endothermic (heat is absorbed from the surroundings by the system) reaction. Electrical energy is used to split the water into hydrogen and oxygen molecules. Temperature plays an important role on water electrolysis. Pure water electrolysis is not thermodynamically favored as it is a good insulator [9]. In standard condition the reaction is as follows

Anode (oxidation):

$$
2 \mathrm{H}_{2} \mathrm{O} \rightarrow \mathrm{O}_{2}(g)+4 \mathrm{H}^{+}(\mathrm{aq})+4 \mathrm{e}^{-} \mathrm{E}_{0}=+1.23 \mathrm{~V}
$$

Cathode (reduction):

$$
2 H^{+}(\text {aq })+2 e^{-} \rightarrow H_{2}(g) ; E_{0}=0 \mathrm{~V}
$$


So the required cell voltage becomes

$$
E_{\text {cell }}=E_{\text {cathode }}-E_{\text {anode }}=0 \mathrm{~V}-1.23 \mathrm{~V}=-1.23 \mathrm{~V}
$$

(at $25^{\circ} \mathrm{C} \mathrm{pH} 0[\mathrm{H}+=1.0 \mathrm{M}]$ )

According to the Nernst equation the cell potential is same for $25^{\circ} \mathrm{C}$ with pH $7\left([\mathrm{H}+]=1.0 \times 10^{-7} \mathrm{M}\right)$

Nernst equation is derived from the change of Gibbs free energy in standard condition.

The Nernst equation for half-cell

$$
E_{\text {red }}=E_{\text {red }}^{0}-\frac{F T}{z F} \ln (Q)
$$

The full cell equation is similar

$$
E_{\text {cell }}=E_{\text {cell }}^{0}-\frac{\mathbb{R T}}{g F} \ln \left(Q_{r}\right)
$$

Here, Ered is the half-cell reduction potential at the temperature of interest, $E_{\text {red }}^{0}$ is the standard half-cell reduction potential, $E_{\text {cell }}$ is the cell potential (electromotive force) at the temperature of interest, $E_{\text {cell }}^{0}$ is the standard cell potential, $\mathrm{R}$ is the universal gas constant: $\mathrm{R}=8.314472(15)$ $\mathrm{JK}-1 \mathrm{~mol}-1, \mathrm{~T}$ is the temperature in kelvin

Gibbs free energy Change, $\Delta G$ is a function of standard condition free energy change, $\Delta G^{0}$ by the relation,

$$
\Delta G=\Delta G^{0}+R T \ln (Q)
$$

Where, $\Delta G=-z F E \Rightarrow=\frac{\Delta G}{z F}$; hence $E^{0}=\frac{\Delta G^{0}}{z F}$ which implies the Nernst equation.

Here, $\mathrm{F}$ is the Faraday constant, the number of coulombs per mole of electrons: $\mathrm{F}=9.64853399(24) \times 104 \mathrm{C} \mathrm{mol}-1, \mathrm{z}$ is the number of electrons transferred in the cell reaction or half-reaction, $Q_{r}$ is the reaction quotient of the cell reaction.

In practical cases separation of water elements does not simply starts at 1.23 volts. There are a handful number of issues and conditions which in fact have influences on electrolysis. Electrolysis starts at a certain voltage level dependent on system's intrinsic and extrinsic conditions [10]. The minimum energy required to start electrolysis is known as Gibbs free energy. The term free energy represents the available energy in a system. This is a very well-known term in thermodynamics. The required voltage needs to start the separation of hydrogen and oxygen is known as the reversible voltage. In the range between the zero level and reversible potential the generation of hydrogen is not possible.

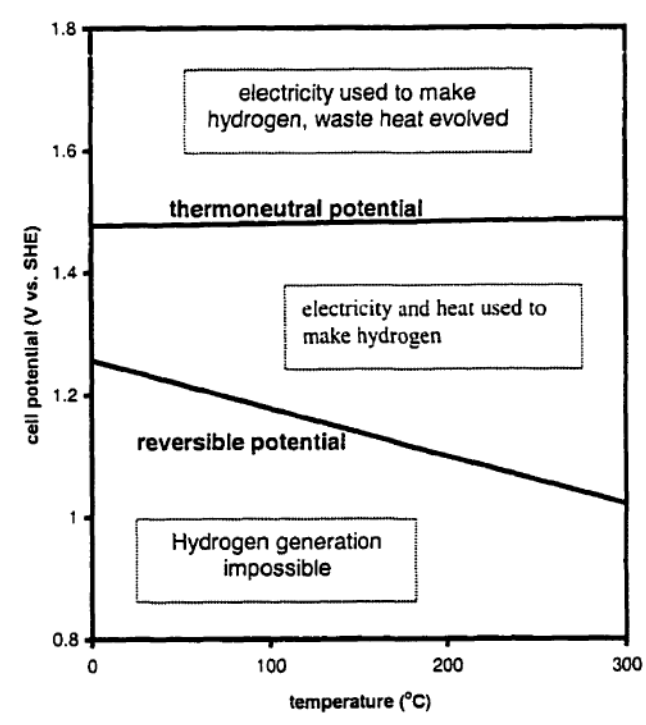

Fig.1. Ideal Characteristics of Electrolysis.

The overall cell voltage is comprised of reversible voltage, anode over potential, cathode over potential and inter electrode Ohmic drop [11]. The expression below shows the relationship of these active voltage components of cell voltage. "Fig.1 shows ideal conditions for general electrolysis.

$$
V_{\text {cell }}=V_{\text {rev }}+V_{\text {anode }}+V_{\text {cathode }}+V_{\text {ohm }}
$$

The reaction enthalpy denotes the minimum energy required for the start of the reaction.

$$
E_{\text {Gibbs }}=\text { Work done }+ \text { heat }
$$

The efficiency of water electrolysis is largely dependent on the supply voltage. Over voltage produces extra heat which does not contribute to the generation of hydrogen gas. This phenomenon results waste of energy [12]. The most efficient voltage point for water electrolysis is known as thermo-neutral point. At which the electricity and heat both contribute to gas generation. Above this condition electricity is wasted as heat. The thermos-neutral voltage is said to be around $1.48 \mathrm{~V}$. This voltage might be dependent on system characteristics [13].

Another issue relates the practical condition for electrolyzing device is over potential. This is a difference between the required voltage for half reaction in ideal condition and the voltage required for the practical setup [14]. This occurs both in anode and cathode.

Ohmic drop due to the resistivity of electrode material. There are other micro components of this deviation from standard case. Like activation polarization over voltage and concentration polarization overvoltage which can be seen under the over potential requirement for electrolysis [15].

The reversible potential may have been altered by changing the system configuration like electrode gap, molarity, system temperature, types of electrode material, geometry of electrode etc which will be investigated and observed in this experiment. Along with these other characteristics and behavior of electrolysis with respect to different conditions will be studied in this experiment. 


\section{Methodology}

To observe performance determining key parameters some variables are selected. Applied voltage, size of electrodes, and separation gap of electrodes and molarity of sodium hydroxide solutions are considered as variables. Current distribution or consumption by the electrolyzer and gas production rate are the measuring values to determine the key performance for a known setting. Stainless steel of 300L grade is used to construct the electrodes of different sizes [16]. Standard sodium hydroxide $(\mathrm{NaOH})$ solutions of different molarities were used. Applied voltage was varied after 3 minutes for a particular setup of apparatus, Change in Current consumption, temperature and gas production was recorded after three minute interval.

Recorded data is tabulated and the performance parameters are compared for each condition. Some key results and tables are presented in this paper with comments. Considering the use of solar panels as the source of power for the electrolyzer the effect of voltage deviation has also been observed and discussed.

\section{A. Testing Instrument and setup}

A dedicated test setup was developed to complete this task. The setup is mainly a glass jar having two compartments. Electrodes can be fixed with two connecting lids. The connecting lids are designed to vary the separation gap between attached electrodes. Two temperature sensors are inserted from the top of the jar. The jar is air tight from all sides. A separator frame is deployed in center which can hold a membrane. The task of membrane is to separate the gases [17]. Two gas outlet channels are provided so that the collection gas can be smooth. The design of the developed instrument is shown in "Fig. 2".

\section{OBSERVATION OF PARAMETER CHARACTERISTICS}

Applied voltage is the primary variable against which current distribution and gas production were observed. A standard variable voltage source was used to feed the system. Applied voltage was changed in a predetermined manner.

\section{A. Current Distribution}

According to the recorded data it has been found that the increment of voltage results linear increment of current in a certain molarities solution of $\mathrm{NaOH}$. Size of electrode increases the current distribution.

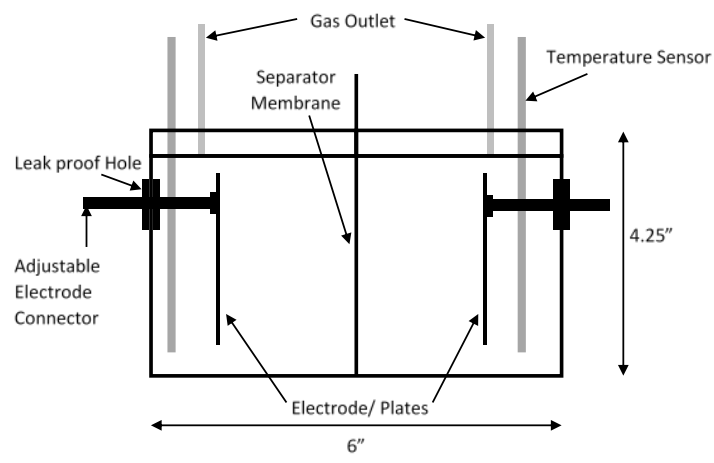

Fig.2. Test Electrolyser

\section{B. Gas Production Behavior}

The more the system absorbs current would produce the more gas or hydrogen. However there is a limit for the linearity. To a certain voltage stress or the current distribution a particular system would use electrical energy to split the water. After that range the extra energy would increase the temperature of the system.

\section{Temperature Change}

Temperature during the reaction does not change drastically. But there is a certain limit of applied voltage after which temperature gets increased [18]. At this point gas production rate gets decreased. Which is found matched with the theoretical explanations. The increment of temperature is proportional to the increment of voltage. The testing apparatus was not insulated and cooled with the ambient.

\section{Solution Characteristics}

New solutions are the most productive. Every solution gives proper data up to four times of use. It gets weaker gradually. This is because of the impurities gets mixed with the solution [19]. Most of the impurities are found dust particles, silicon compound, iron and other traces.

\section{EFFECT OF MOLARITY CHANGE}

Molarity effect represents the change of electrolyzer performance with the change of molarities of $\mathrm{NaOH}$ where all other conditions remain same. Here, other condition means the same size electrode and same separation gap between two electrodes.

\section{A. Current Distribution}

Current distribution for this condition is found decreasing with the decrease of molarity. "Fig.3" shows that the difference between $1.5 \mathrm{M}$ and $1.0 \mathrm{M}$ is not very wide whereas for $0.5 \mathrm{M}$ and $0.25 \mathrm{M}$. Table I present Sample Data of Current on molarity Change.

TABLE I

Sample Data of CurRent on Molarity Change

\begin{tabular}{|c|c|c|c|c|}
\hline Voltage & $\begin{array}{c}\mathbf{1 . 5 M} \\
\text { (amp) }\end{array}$ & $\begin{array}{c}\mathbf{1 . 0 M} \\
\text { (amp) }\end{array}$ & $\begin{array}{c}\mathbf{0 . 5 M} \\
\text { (amp) }\end{array}$ & $\begin{array}{c}\mathbf{0 . 2 5 M} \\
\text { (amp) }\end{array}$ \\
\hline 1 & 0.00 & 0.00 & 0.00 & 0.00 \\
\hline 1.3 & 0.00 & 0.00 & & \\
\hline 1.5 & & & 0.03 & \\
\hline 1.6 & 0.02 & 0.02 & & \\
\hline 1.7 & & & & 0.03 \\
\hline 1.9 & 0.07 & 0.07 & & \\
\hline 2 & & & 0.09 & \\
\hline 2.2 & 0.29 & 0.35 & & \\
\hline 2.4 & & & & 0.17 \\
\hline 2.5 & 0.71 & 0.67 & 0.40 & \\
\hline 2.7 & 1.09 & & & \\
\hline 2.8 & & 1.06 & & \\
\hline 3 & & & 0.78 & \\
\hline 3.1 & 1.50 & 1.46 & & 0.42 \\
\hline 3.4 & 1.87 & 1.85 & & \\
\hline 3.5 & & & 1.19 & \\
\hline 3.7 & 2.34 & & & \\
\hline 3.8 & & 2.38 & & 0.67 \\
\hline 4 & 2.74 & & 1.53 & \\
\hline 4.1 & & 2.72 & & \\
\hline 4.3 & 3.16 & & & \\
\hline 4.4 & & 3.16 & & \\
\hline
\end{tabular}


Practical Study of Water Electrolysis for Solar Powered Hydrogen Production Using Stainless Steel Electrode and Sodium Hydroxide Solution

\begin{tabular}{|c|l|l|l|l|}
4.5 & & & 1.94 & 0.90 \\
\hline 5 & & & 2.37 & \\
\hline 5.2 & & & & 1.19 \\
\hline 5.5 & & & 2.80 & \\
\hline 5.9 & & & & 1.47 \\
\hline 6 & & & 3.16 & \\
\hline 6.6 & & & & 1.79 \\
\hline 7.3 & & & & 2.02 \\
\hline 8 & & & & 2.31 \\
\hline 8.7 & & & & 2.58 \\
\hline 9.4 & & & & 2.89 \\
\hline 10 & & & & 3.16 \\
\hline
\end{tabular}

Type 5, $8 \mathrm{~cm}$ Seperation

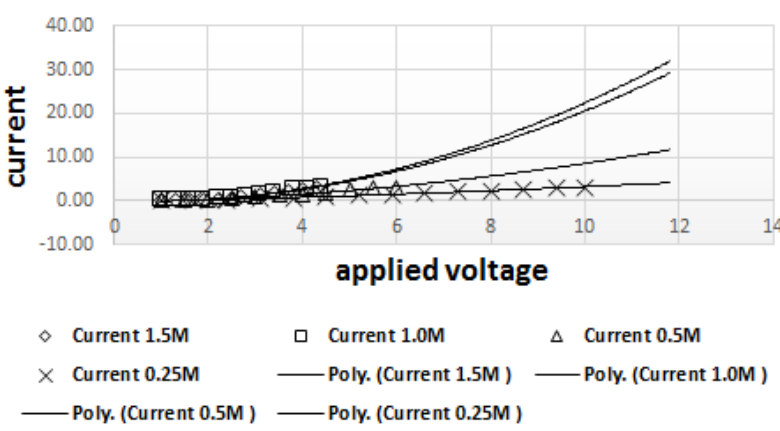

Fig.3. Current Distribution on Molarity Change

\section{B. Gas Production}

According to recorded data the gas production rate increased with the increase in molarity. "Fig.4" shows that the gas production rate for $1.0 \mathrm{M}$ solution is higher than $1.5 \mathrm{M}$. The reason behind this result is because of the aging effect of the solution [20]. Used 1.5M solution here was older than the solution of $1.0 \mathrm{M}$. The $1.5 \mathrm{M}$ solution was used for more than 4 times to test the same procedure. Table II presents Sample Data of gas production rate on molarity Change.

TABLE II

Sample Data of Gas PRoduction on Molarity Change

\begin{tabular}{|c|c|c|c|c|}
\hline Voltage & $\begin{array}{c}\mathbf{1 . 5 M} \\
(\mathbf{m L} / \mathbf{m i n})\end{array}$ & $\begin{array}{c}\mathbf{1 . 0 M} \\
(\mathbf{m L} / \mathbf{m i n})\end{array}$ & $\begin{array}{c}\mathbf{0 . 5 M} \\
(\mathbf{m L} / \mathbf{m i n})\end{array}$ & $\begin{array}{c}\mathbf{0 . 2 5 M} \\
(\mathbf{m L} / \mathbf{m i n})\end{array}$ \\
\hline 1 & 0.00 & 0.00 & 0.00 & 0.00 \\
\hline 1.3 & 0.00 & 0.00 & & \\
\hline 1.5 & & & 0.00 & \\
\hline 1.6 & 0.00 & 0.00 & & \\
\hline 1.7 & & & & 0.00 \\
\hline 1.9 & 0.00 & 0.00 & & \\
\hline 2 & & & 0.00 & \\
\hline 2.2 & 0.00 & 2.67 & & \\
\hline 2.4 & & & & 0.00 \\
\hline 2.5 & 0.00 & 5.67 & 1.67 & \\
\hline 2.7 & 3.33 & & & \\
\hline 2.8 & & 15.00 & & \\
\hline 3 & & & 6.67 & \\
\hline 3.1 & 10.00 & 20.00 & & 1.67 \\
\hline 3.4 & 15.00 & 28.33 & & \\
\hline 3.5 & & & 15.00 & \\
\hline 3.7 & 23.33 & & & \\
\hline 3.8 & & 28.33 & & 8.33 \\
\hline 4 & 28.33 & & 23.33 & \\
\hline 4.1 & & 43.33 & & \\
\hline
\end{tabular}

\begin{tabular}{|c|c|c|c|c|}
\hline 4.3 & 36.67 & & & \\
\hline 4.4 & & 46.67 & & \\
\hline 4.5 & & & 30.00 & 10.00 \\
\hline 5 & & & 33.33 & \\
\hline 5.2 & & & & 16.67 \\
\hline 5.5 & & & 80.00 & \\
\hline 5.9 & & & & 26.67 \\
\hline 6 & & & 126.67 & \\
\hline 6.6 & & & & 23.33 \\
\hline 7.3 & & & & 33.33 \\
\hline 8 & & & & 33.33 \\
\hline 8.7 & & & & 46.67 \\
\hline 9.4 & & & & 40.00 \\
\hline 10 & & & & 56.67 \\
\hline
\end{tabular}

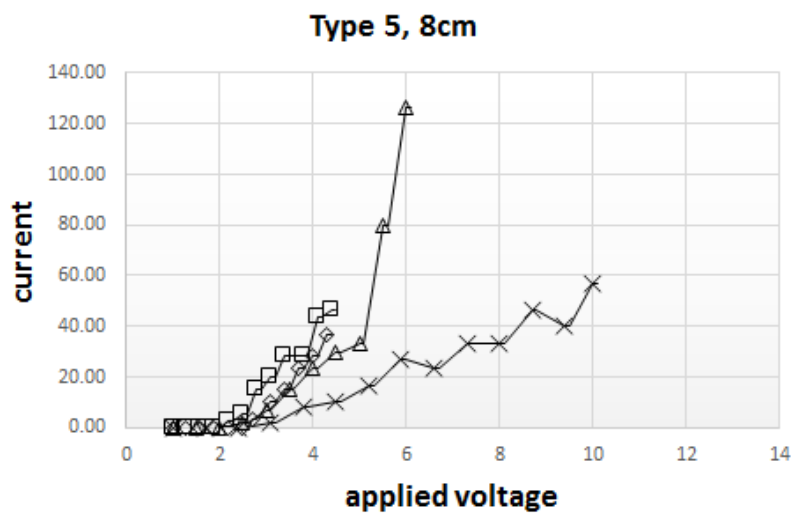

\footnotetext{
$\diamond$ Production Rate 1.5M

口 Production Rate 1.0M

$\triangle$ Production Rate 0.5M

$\times$ Production Rate $0.25 \mathrm{M}$

2 per. Mov. Avg. (Production Rate 1.5M)

-2 per. Mov. Avg. (Production Rate 1.0M)

2 per. Mov. Avg. (Production Rate 0.5M)

2 per. Mov. Avg. (Production Rate $0.25 \mathrm{M}$ )
}

Fig.4. Gas Production on Molarity Change

\section{Change of Electrode GaP}

Electrode gap was decreased after each set of test. The closest separation forms higher current distribution throughout the solution as well as electrode surface shown in "Fig.5". It is notable that all other conditions should remain same. TABLE III contains Sample Data of Current on Gap Change.

TABLE III

SAMPLE DATA OF CURRENT ON GAP CHANGE

\begin{tabular}{|c|c|c|c|c|}
\hline Voltage & $\mathbf{1 0} \mathbf{c m}(\mathbf{a m p})$ & $\mathbf{8 c m}(\mathbf{a m p})$ & $\mathbf{6 c m}(\mathbf{a m p})$ & $\mathbf{4 c m}(\mathbf{a m p})$ \\
\hline 1 & 0.00 & 0.00 & 0.01 & 0.00 \\
\hline 1.3 & 0.00 & 0.00 & 0.00 & 0.00 \\
\hline 1.6 & 0.00 & 0.02 & 0.03 & 0.03 \\
\hline 1.9 & 0.11 & 0.07 & 0.10 & 0.07 \\
\hline 2.2 & 0.21 & 0.29 & 0.43 & 0.42 \\
\hline 2.5 & 0.53 & 0.71 & 1.02 & 1.04 \\
\hline 2.7 & & 1.09 & & \\
\hline 2.8 & 0.95 & & 1.53 & 1.78 \\
\hline 3.1 & 1.32 & 1.50 & 2.18 & 2.43 \\
\hline 3.4 & 1.71 & 1.87 & 2.64 & 3.16 \\
\hline 3.6 & & & 3.17 & \\
\hline 3.7 & 2.07 & 2.34 & & \\
\hline 4 & 2.44 & 2.74 & & \\
\hline
\end{tabular}


International Journal of New Technology and Research (IJNTR) ISSN: 2454-4116, Volume-5, Issue-3, March 2019 Pages 84-90

\begin{tabular}{|l|l|l|l|l|}
4.3 & 2.83 & 3.16 & & \\
\hline 4.5 & 3.08 & & & \\
\hline 4.6 & 3.16 & & & \\
\hline
\end{tabular}

\section{A. Current Distribution}

Type 5, 1.5M

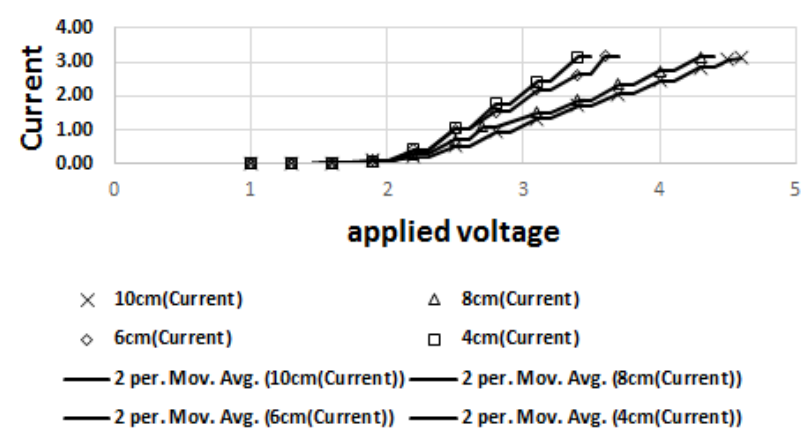

Fig.5. Current Distribution on Gap Change

TABLE IV

SAMPle Data of Gas Production on Gap Change

\begin{tabular}{|c|c|c|c|c|}
\hline Voltage & $\begin{array}{c}\mathbf{1 0 c m} \\
(\mathbf{m L} / \mathbf{m i n})\end{array}$ & $\begin{array}{c}\mathbf{8 c m} \\
(\mathbf{m L} / \mathbf{m i n})\end{array}$ & $\begin{array}{c}\mathbf{6 c m} \\
(\mathbf{m L} / \mathbf{m i n})\end{array}$ & $\begin{array}{c}\mathbf{4 c m} \\
(\mathbf{m L} / \mathbf{m i n})\end{array}$ \\
\hline 1 & 0.00 & 0.00 & 0.00 & 0.00 \\
\hline 1.3 & 0.00 & 0.00 & 0.00 & 0.00 \\
\hline 1.6 & 0.00 & 0.00 & 0.00 & 0.00 \\
\hline 1.9 & 0.00 & 0.00 & 0.00 & 0.00 \\
\hline 2.2 & 0.00 & 0.00 & 0.67 & 1.67 \\
\hline 2.5 & 1.67 & 0.00 & 8.67 & 11.67 \\
\hline 2.7 & & 3.33 & & \\
\hline 2.8 & 11.00 & & 17.33 & 26.67 \\
\hline 3.1 & 17.33 & 10.00 & 28.33 & 38.33 \\
\hline 3.4 & 23.33 & 15.00 & 32.33 & 43.33 \\
\hline 3.6 & & & 42.67 & \\
\hline 3.7 & 26.67 & 23.33 & & \\
\hline 4 & 33.33 & 28.33 & & \\
\hline 4.3 & 36.67 & 36.67 & & \\
\hline 4.5 & 40.00 & & & \\
\hline 4.6 & 43.33 & & & \\
\hline
\end{tabular}

\section{B. Gas Production}

Gas production rate and behavior depend on the separation gap. Lower gap results higher production rate, see "Fig.6". Observed data shows linear relationship between results. TABLE IV shows Sample Data of Gas Production on Gap Change.

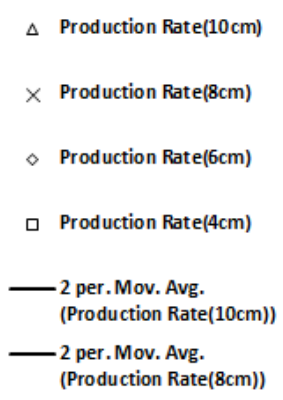

\section{Type 5, 1.5M}

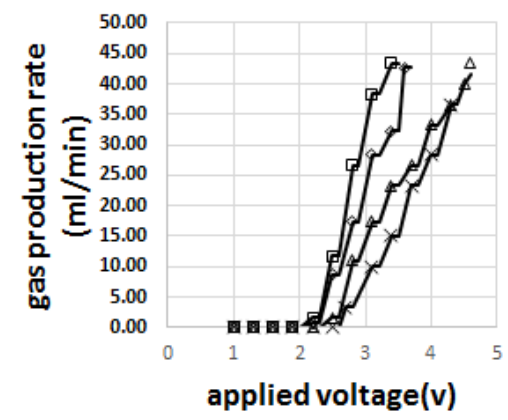

Fig.6. Gas Production on Gap Change

\section{SIZE OF Electrode}

Current characteristics vary with the size of electrodes. It is because of the effective surface area of the electrode. Larger the size of electrode surface higher the current distribution was found see "Fig.7". TABLE V shows sample data of current distribution on Electrode Size Change.

TABLE V

SAmple Data of CurRent on Electrode Size Change

\begin{tabular}{|c|c|c|c|}
\hline Voltage & Type1(amp) & Type3(amp) & Type5(amp) \\
\hline 1 & 0 & 0.00 & 0.00 \\
\hline 1.7 & 0.02 & 0.01 & 0.03 \\
\hline 2.4 & 0.165 & 0.23 & 0.31 \\
\hline 3.1 & 0.48 & 0.61 & 0.80 \\
\hline 3.8 & 0.83 & 1.05 & 1.27 \\
\hline 4.5 & 1.16 & 1.49 & 1.76 \\
\hline 5.3 & 1.5 & 1.91 & 2.28 \\
\hline 6 & 1.9 & 2.40 & 2.77 \\
\hline 6.5 & & & 3.16 \\
\hline 6.7 & 2.265 & 2.88 & \\
\hline 7.1 & & 3.16 & \\
\hline 7.4 & 2.615 & & \\
\hline 8.1 & 3 & & \\
\hline 8.3 & 3.16 & & \\
\hline
\end{tabular}

\section{A. Current Characteristics}

\section{$0.25 \mathrm{M}, 4 \mathrm{~cm}$}

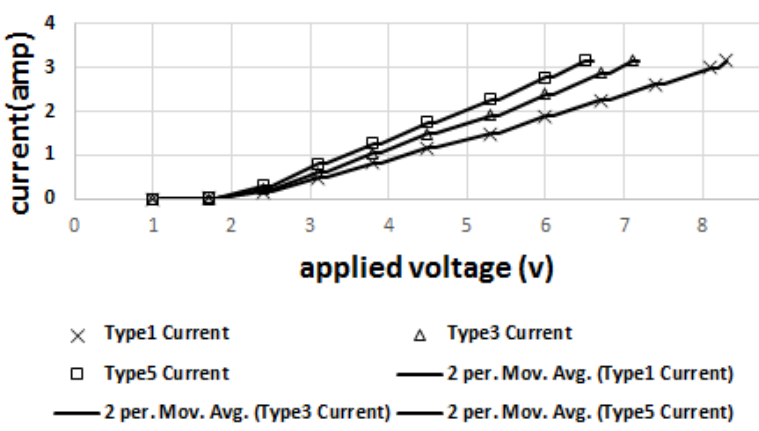

Fig.7. Current Distribution on Electrode Size Change

B. Gas Production

TABLE VI

Sample Data of Gas Production Rate on Electrode Size ChANGe

\begin{tabular}{|c|c|c|c|}
\hline Voltage & $\begin{array}{c}\text { Type 1 } \\
\text { (mL/min) }\end{array}$ & $\begin{array}{c}\text { Type 3 } \\
\text { (mL/min) }\end{array}$ & $\begin{array}{c}\text { Type 5 } \\
\text { (mL/min) }\end{array}$ \\
\hline 1 & 0.00 & 0.00 & 0.00 \\
\hline 1.7 & 0.00 & 0.00 & 0.00 \\
\hline 2.4 & 0.00 & 0.00 & 1.67 \\
\hline 3.1 & 3.33 & 3.33 & 1.67 \\
\hline 3.8 & 10.00 & 13.33 & 16.67 \\
\hline 4.5 & 16.67 & 16.67 & 23.33 \\
\hline
\end{tabular}




\begin{tabular}{|c|c|c|c|}
5.3 & 20.00 & 30.00 & 20.00 \\
\hline 6 & 26.67 & 33.33 & 40.00 \\
\hline 6.5 & & & 33.33 \\
\hline 6.7 & 30.00 & 36.67 & \\
\hline 7.1 & & 45.00 & \\
\hline 7.4 & 33.33 & & \\
\hline 8.1 & 46.67 & & \\
\hline 8.3 & 46.67 & & \\
\hline
\end{tabular}

Gas production depends on the effective surface area of the electrode. It is found that the higher the surface area, higher the production rate. "Fig. 8 " shows some deflected data on electrode size change effect. This is because of some data recording error. The error relates to the measured time interval between data accumulation.

\section{$0.25 \mathrm{M}, 4 \mathrm{~cm}$}
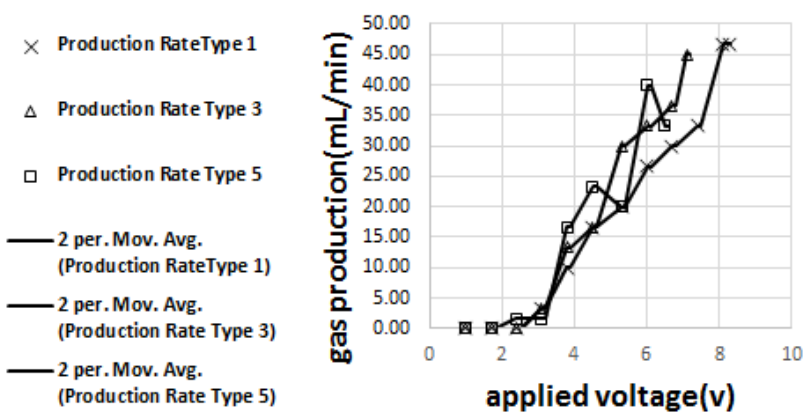

Fig.8. Gas Production on Electrode Size Change

\section{Voltage SWING TeSt FOR SOlar POWER APPLICATION ASSESSMENT}

Stress test results would comment on the systems behavior when the hydrogen generator is powered from solar panels [21]. Naturally the power output from solar panels varies with weather conditions [22]. Sometimes the voltage level goes higher and sometimes it gets lowered with accordance to the solar radiation. The objective of this test is to observe data with a variable power source. TABLE VII shows sample data of voltage swing test.

TABLE VII

SAMPLE DATA OF SWING TeSt

\begin{tabular}{|c|c|c|c|}
\hline $\begin{array}{c}\text { Applied } \\
\text { Voltage } \\
(\mathbf{V})\end{array}$ & $\begin{array}{l}\text { Curren } \\
\mathbf{t} \\
(\text { Amp) }\end{array}$ & $\begin{array}{c}\text { Temperatur } \\
\mathbf{e}\left({ }^{\mathbf{0}} \mathbf{C}\right)\end{array}$ & $\begin{array}{c}\text { Gas Production } \\
\text { Rate } \\
(\mathbf{m L / m i n})\end{array}$ \\
\hline 2.55 & 1.23 & 35 & 9.75 \\
\hline 3.2 & 2.43 & 35 & 9.75 \\
\hline 2.55 & 1.25 & 35 & 18.75 \\
\hline 3.5 & 3.16 & 35 & 25.00 \\
\hline 2.55 & 1.30 & 35 & 20.00 \\
\hline
\end{tabular}

\section{A. Current Characteristics}

Voltage level was increased and decreased in a fashioned manner so that the change can be identified. It is observed that any sudden increase can boost up the current distribution along with the gas production. It remains at the same distribution at a specific voltage even after having a voltage swing, see "Fig.9".
Type 5, 1.0M

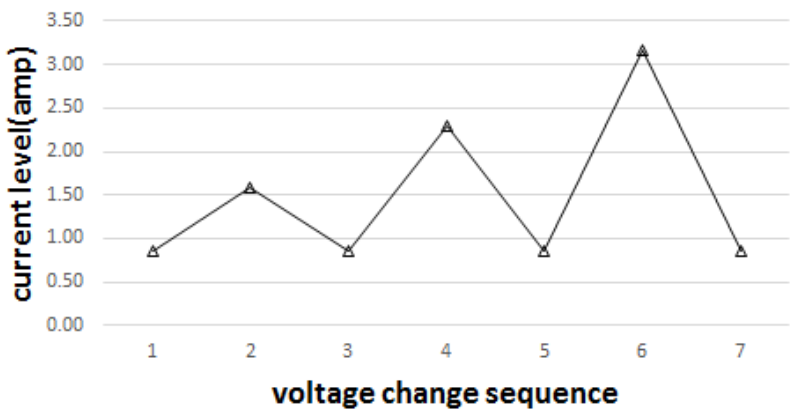

Fig.9. Current Distribution on Voltage Swing

\section{B. Gas production Characteristics}

However the production gets some increment which is diminished over a short period of time, see "Fig.10". This time can be described as the equalizing period of electron for a voltage overshoot.

\section{Type 5, 1.0M}

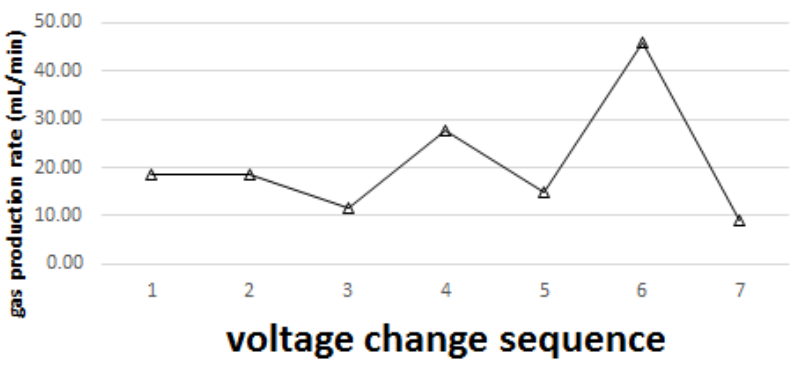

Fig.10. Current Distribution on Voltage Swing

\section{CONCLUSION}

The overall test is carried out to find several dependencies and characteristics of electrolysis parameter. It is found that the higher molarity can boost the electrolysis speed and gas production. The electrode size can regulate the electrolysis. Less separation gap can accelerate the reaction and current distribution would be higher for closer electrodes. Importantly the scheme is aimed to have solar photovoltaic panels as its main power source. The fluctuation of voltage has no negative impact on the gas production during sodium hydroxide based water electrolysis.

\section{ACKNOWLEDGMENT}

This research is done under the supervision of Professor Dr. Saiful Huque, Institute of Energy, University of Dhaka at IE Lab. The works is not funded by any government, semi-government or any other organization.

\section{REFERENCES}

[1] Freedonia Group, Inc. (2010), "World Hydrogen Demand and 2013 Forecast," February.

[2] US Energy Information Administration (EIA) (2008), "The Impact of Increased Use of Hydrogen on Petroleum Consumption and Carbon Dioxide Emissions," Report No: SR-OIAF-CNEAF/2008-04, www.eia.doe.gov/oiaf/servicerpt/hydro/appendixc.html, August.

[3] US Department of Energy (2010), "The Department of Energy Hydrogen and Fuel Cells Program Plan An Integrated Strategic Plan 
for the Research, Development, and Demonstration of Hydrogen and Fuel Cell Technologies - DRAFT."

[4] W. keuter and H. Hofmann, Electroiysis: The Important Energy Transformer in a world of Sustainable Energy, International Journal of Hydrogen Energy, Vol. 23. No 8, pp. 661-666, Elsevier Science Ltd., 1998.

[5] R. Gilliam, J. Graydon, D. Kirk, and S. Thorpe, International Journal of Hydrogen Energy, 32, 359, 2007.

[6] R. Renaud and R. Leroy, International Journal of Hydrogen Energy, 7, $155,1982$.

[7] H. Wendt and H. Hofmann, J. Appl. Electrochem., 19, 605, 1989.

[8] M. Faraj et al., International Journal of Hydrogen Energy, 37, 14992, 2012.

[9] Y. Leng et al., J. Am. Chem. Soc., 134, 9054, 2012.

[10] P. J. Sides, Phenomena and Effects of Electrolytic Gas Evolution. Modem Aspects of electrochemistry, Vol. 18. (ed. White, R. E. Bockris. I. O. M., and Conway, B. E.), Plenum Press, New York, p. 303-354, 1986.

[11] J. L. Fernandez, M. R. de Chilvo, and A. C. Chilvo. Preparation and electrochemical characterization of ti/ruxmn1-xo2 electrodes. Journal of Applied Electrochemistry, 32:513-520, 2002.

[12] H. Beer, P. Borrow, and R. Brsi, , Neocleate Boiling: Bubble Growth and Dynamics, Heat Transfer in Boiling, Hahne, H. and Grigull, 5 ed., New York, Academic Press, p. 71-52, L977.

[13] S. Bongenaar, L. J. M. Konings,., C. I. Smeyen, J. H. G. Verbunt, E. Barendrecht, L J. J. Janssen, W. M. Sluyter, and S. J. D. Sualen, Ohmic Potential Drop and Gus Bubble Radious Distribution in alkaline Water Electrolysis, Proceedings of 3d Int. Seminar. Hydrogen as Energy Carrier, Lyon, 25-27 May 1983, p. 206, 1983.

[14] T. Atsushi, Energy Carriers AND Conversion Systems Encyclopaedia of Life Support Systems (EOLSS) Thermodynamics of Water Splitting,Vol. I.

[15] B. V. Tilak, P. W. T. Lu, J. E. Colman, and S. Srinivasan, Electrolytic Production of Hydrogen, Comprehensive Treatise of Electrochemistry, Vol. 2. (Ed. Bockris, J. O. M., Conway, B. E., Yeager, E., White. R. E.), Plenum Press. New York and London, , p. 1., 1983.

[16] Ramacgandran. R., and Menon, R. K., An Overview of Inclustriai Uses of Hydrogen, Int. J. Hydrogen Energy, Vol. 23, No. 7, pp. 593-598, Elsevier Science Ltd., 1998.

[17] D. Hart, L. Bertuccioli, and X. Hansen, Policies for Storing Renewable Energy A Scoping Study of Policy Considerations for Energy Storage (Re-Storage), IEARenewable Energy Technology Deployment, 2016.

[18] C. Mittelsteadt, T. Norman, M. Rich, and J. Willey, in Electrochemical Energy Storage for Renewable Sources and Grid Balancing, P. T. Moseley and J. Garche Editors, p. 159, Elsevier, 2015.

[19] L. Bertuccioli, A. Chan, D. Hart, F. Lehner, B. Madden, and E. Standen, Study on Development of Water Electrolysis in the EU by E4tech S`arl with Element Energy Ltd for the Fuel Cells and Hydrogen Joint Undertaking, 2014.

[20] C. S. Gittleman, F. D. Coms and Y. H. Lai, Polymer Electrolyte Fuel Cell Degradation, M. M. Mench, E. C. Kumbur, and T. N. Veziroglu Editors, p. 15, Academic Press, Boston, 2012.

[21] D. F. Abbott, D. Lebedev, K. Waltar, M. Povia, M. Nachtegaal, E. Fabbri, C. Cop'eret, and T. J. Schmidt, Chemistry of Materials, 28, 6591, 2016.

[22] M. Carmo, D.L. Fritz, J. Mergel, and D. Stolten, International Journal of Hydrogen Energy, 38, 4901, 2013. 